\title{
59. Chromosomal Studies on Interspecific Hybrids of Butterflies (Papilionidae, Lepidoptera). XV
}

\author{
Crosses among Papilio machaon gorganus, P. machaon \\ hippocrates, P. machaon britannicus, P. oregonius, \\ P. bairdii, and P. rudkini
}

\author{
By Kodo MAEkI*) and Shigeru A. AE**) \\ (Communicated by Sajiro Makino, M. J. A., June 12, 1979)
}

\begin{abstract}
Among six species of Papilio machaon group here under consideration, the larvae of Papilio bairdii and $P$. oregonius grow well on Artemisia plant in the districts of the Rocky Mountains, while the larvae of the following 4 species ( $P$. machaon gorganus, $P$. machaon hippocrates, $P$. machaon britannicus, and $P$. rudkini) subsist on the leaves of Umbelliferae in the Holarctic regions. A cytogenetical study with particular regard to species-relationship in the above-mentioned butterfly species is to be dealt with as a major subject in this paper. During the past several years our interest has been concentrated around this problem, especially on the significance of chromosomal pairing in male meiosis of $F_{1}$ hybrids from the standpoint of genic homology. In the previous papers, relevant data have been presented on the meiotic behavior of chromosomes in $F_{1}$ hybrids produced artificially in the following crosses among Papilio polyctor, $P$. bianor, $P$. maacki, $P$. polytes, $P$. alphenor, $P$. hipponous, $P$. paris, $P$. helenus, $P$. protenor, $P$. macilentus, $P$. nepheles, $P$. aegeus, $P$. fuscus, $P$. memnon, $P$. lowi, $P$. ascalaphus, $P$. polymnestor, $P$. rumanzovia, $P$. machaon hippocrates, $P$. machaon gorganus, $P$. machaon britannicus, $P$. xuthus, $P$. benguetana, $P$. polyxenes and $P$. zelicaon (Maeki and Ae 1964, 1966, 1970, 1975, 1976a-d, 1977a-c, 1978a-b, 1979a-b).

The present article represents some aspects on the meiotic features of chromosomes in the $\mathrm{F}_{1}$ hybrids from the crosses between the following six species, Papilio machaon gorganus, P. machaon hippocrates, $P$. machaon britannicus, $P$. bairdii, $P$. oregonius, and $P$. rudkini. Two of the six species, $P$. machaon hippocrates from Japan and $P$. machaon britannicus from England, were remarkable by the occurrence of supernumerary, or B, chromosomes which varied from 1 to 4 in the first meiotic cells. The other 4 species were found to

*) The Biological Laboratory, Faculty of Science, the Kwansei Gakuin University, Nishinomiya, Japan.

**) The Biological Laboratory, the Nanzan University, Nagoya, Japan.
\end{abstract}


have uniformly $n, 30$ that is universal in the Papilio members. The hybridization experiments were responsible to Ae (1969), while Maeki took part in the chromosomal investigations. The chromosomes were exclusively studied by the routine paraffin method as in the previous studies.

Results. The major interest in the following was directed toward the meiotic behavior of chromosomes particularly to pairing in $\mathrm{F}_{1}$-hybrids from the following four combinations.

1) Papilio machaon gorganus 우 (from Germany) $\times$ Papilio oregonius of (from U.S.A.). Chromosome counts were made in 12 cells at M-I derived from a single $F_{1}$-hybrid (Go-67-1). The $F_{1}$-hybrid was characterized by the uniform number of $n, 30$ in the first meiotic division (Fig. 1). The chromosomes were remarkable by showing complete pairing at the M-I metaphase. This is a fact indicating that $P$. machaon gorganus and $P$. oregonius are very closely related with each other.

2) Papilio machaon hippocrates 우 (from Japan) $\times$ Papilio bair$d i i$ s (from U.S.A.). Counts of chromosomes in the above cross were carried out in 49 M-I cells which were derived from 2 hybrid males (H-313-1, H-316-2). Histologically the hybrid gonads showed an irregular arrangement of follicles, together with the formation of an accessory gonad rather common to butterfly hybrids. The chromosomes of these $F_{1}$ specimens varied in number from $n, 30$ to $n, 32$ at the first meiosis (Figs. 2-3). The chromosome-number distributions in the M-I metaphase coming from the 49 cells are as follows:

$$
\begin{aligned}
& n, 30 \ldots \ldots .18 \text { cells } \\
& n, 31 \\
& n, 32 \ldots \ldots .22 "
\end{aligned}
$$

The cells having 31 elements were most frequent in incidence as shown by $45 \%$ of the observed cells. The feature is suggestive of that there are many chromosomes which undergo pairing in the first meiosis. On this basis it appears that the parental species are rather closely related with each other.

3) Papilio machaon britannicus 우 (from England) $\times$ Papilio bairdii o (from U.S.A.). In this cross, 90 cells at M-I derived from a single hybrid male (Br-62-1) were available for chromosome study. The chromosome number of the M-I cells in the above specimen ranged in variation from $n, 30$ to $n, 35$ (Figs. $4-7$ ). The cells having 30 elements were most frequent in occurrence, being $37 \%$ in the examined cells. The chromosome-number distributions in the M-I metaphase from the 90 cells are as below:

$$
\begin{aligned}
& n, 30 \ldots \ldots .33 \text { cells } \\
& n, 31 \ldots 22 \text { " }
\end{aligned}
$$




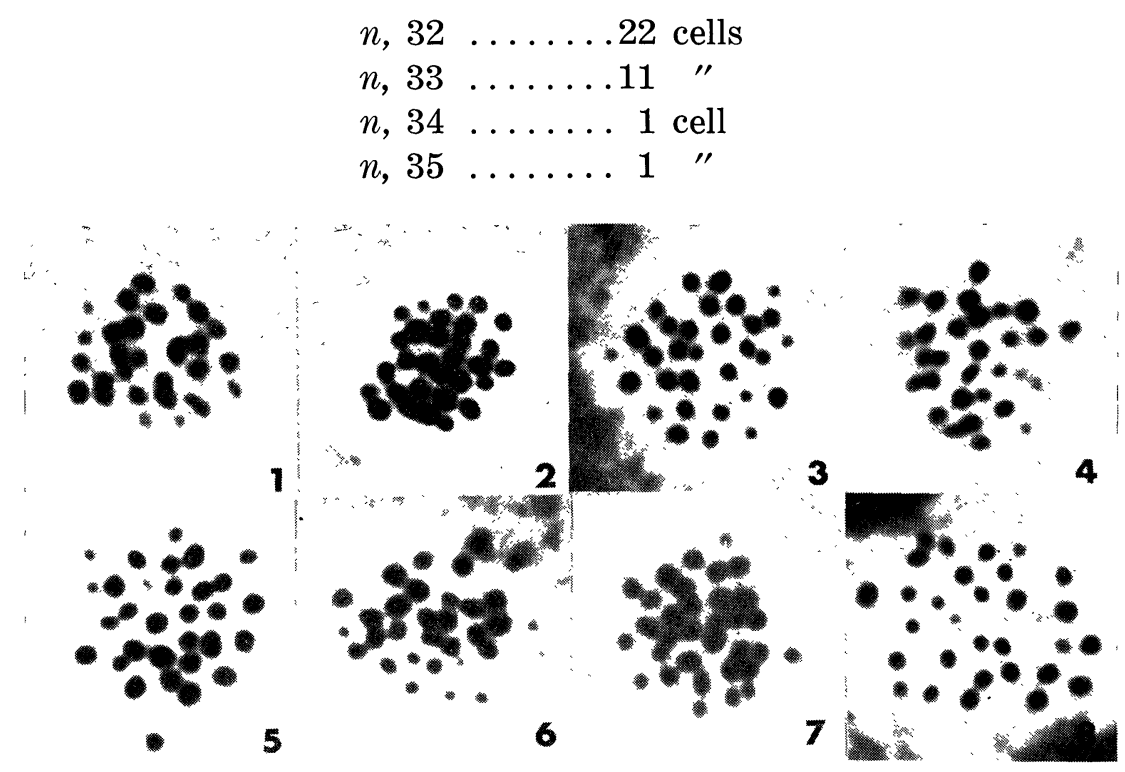

Figs. 1-8. Meiotic chromosomes of Papilio hybrids (M-I, $\times 3500$ ). 1: $P$. machaon gorganus $\times P$. oregonius, $\mathrm{F}_{1}$. 2, 3: P. machaon hippocrates $\times$ $P$. bairdii, $\mathrm{F}_{1}$. 4-7: P. machaon britannicus $\times P$. bairdii, $\mathrm{F}_{1}$. 8: $P$. machaon hippocrates $\times P$. rudkini, $\mathbf{F}_{1}$. 1: $n, 30.2: n, 30.3: n, 31$. 4: $n, 30 . \quad 5: n, 31.6: n, 32 . \quad 7: n, 33 . \quad 8: n, 32$.

4) Papilio machaon hippocrates 우 (from Japan) $\times$ Papilio rudkini o (from U.S.A.). Hybrid chromosomes from the above cross were studied in 8 M-I cells derived from a fifth instar larva (H-311-1). The gonads of this larva were small in size, and cytolysis was remarkable in a large number of cysts. The chromosome number of the M-I cells studied ranged in variation from $n, 31$ to $n, 34$ (Fig. 8 ). The cells showing 32 chromosomes were frequent, being $63 \%$ of cells under study. The chromosome-number distributions obtained in the 8 M-I metaphases are as follows:

$$
\begin{aligned}
& n, 31 \ldots \ldots 1 \text { cell } \\
& n, 32 \ldots \ldots .5 \text { cells } \\
& n, 33 \ldots \ldots 1 \text { cell } \\
& n, 34 \ldots \ldots 1 \text { " }
\end{aligned}
$$

$P$. machaon hippocrates and $P$. m. britannicus used as a parental species in the crosses, (2), (3) and (4), have been known to carry the supernumerary chromosomes which were resulted from fragmentation during spermatogenesis (Maeki 1976). In the hybrids involving $P$. machaon hippocrates and $P$. $m$. britannicus the occurrence of such supernumerary elements has not been detected, so far as our investigations are concerned.

Remarks. Our previous reports have provided the evidence that 
the crosses between $P$. machaon hippocrates $(n, 30-34)$ or $P$. machaon britannicus ( $n, 30-34)$ and the other species of the machaon-group have resulted in $F_{1}$ hybrids which showed the chromosome number of $n, 30$ at M-I as a result of the complete pairing of parental chromosomes (Maeki and Ae 1977b, 1977c). The picture is summarized in the following:

Cross

machaon gorganus $\times$ machaon britannicus

$$
(n, 30) \quad(n, 30-34) \quad 30
$$

machaon gorganus $\times$ machaon hippocrates

$$
(n, 30) \quad(n, 30-34) \quad 30-32
$$

machaon britannicus $\times$ machaon hippocrates

$$
(n, 30-34) \quad(n, 30-34) \quad 30-33
$$

zelicaon $(n, 30) \times$ machaon hippocrates $(n, 30-34)$

polyxenes $\times$ machaon hippocrates

$(n, 30,31)$

$(n, 30-34)$

30-33

It seems very probable that the complete pairing of chromosomes occurring in the M-I cells of the above hybrids is induced by the gametes having $n, 30$ on fertilization. Similarly the $\mathbf{F}_{1}$ from the cross between $P$. machaon gorganus $(n, 30)$ and $P$. polyxenes $(n, 30-31)$ are characterized exclusively by $n, 30$ as a result of the complete pairing of parental chromosomes (Maeki and Ae 1977b).

Based on the above cytogenetic data, as well as on those presented in the hybrids between $P$. machaon hippocrates, P. machaon britannicus, and $P$. bairdii, the following statements may be allowed that the supernumerary chromosomes possessed by the parental species take no part in the meiotic process of their hybrids.

As given in the foregoing descriptions, the variations and modal numbers of the chromosomes obtained in $F_{1}$-males from the present

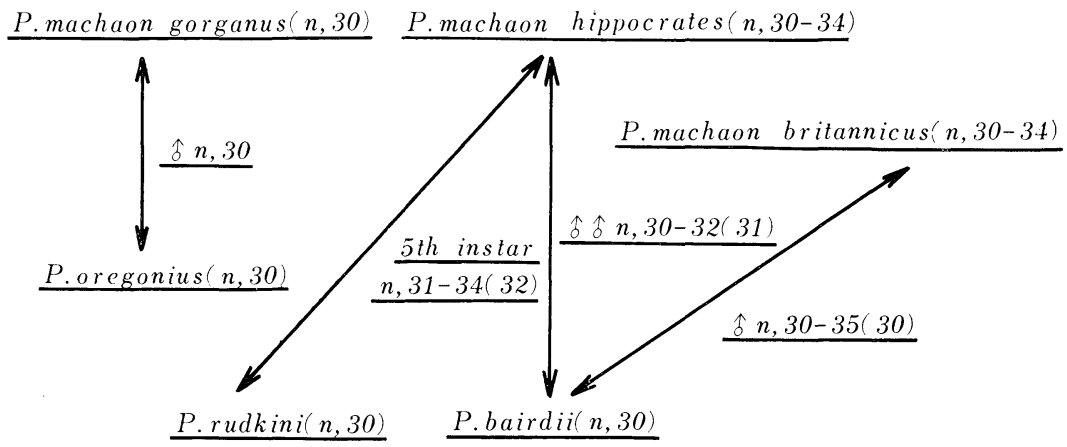

Fig. 9. Diagram illustrating the relationship of 6 species of Papilio here studied, based on the analysis of meiotic pairing of chromosomes in hybrids. 
4 kinds of crosses with the members of the Papilio machaon group were as follows:

\section{Cross}

machaon gorganus $\times$ oregonius machaon hippocrates $\times$ bairdii machaon britannicus $\times$ bairdii machaon hippocrates $\times$ rudkini

$\begin{array}{cc}\text { Number variation } & \text { Mode } \\ 30 & 30 \\ 30-32 & 31 \\ 30-35 & 30 \\ 31-34 & 32\end{array}$

Then, the following conclusion may be possible that, based on the cross experiments in the machaon group concerned, Papilio machaon gorganus and $P$. oregonius are related most closely, and the relation between $P$. machaon hippocrates and $P$. bairdii, that between $P$. machaon britannicus and $P$. bairdii, and that between $P$. machaon hippocrates and $P$. rudkini rank in order, in view of genic homology. A diagram (Fig. 9) is presented to illustrate the above feature. It is to be noted that the members of the machaon group are genetically closely related with each other with no particular reference to the evidence of mimicry as well as to the difference of plants.

Acknowledgements. Our cordial thanks are expressed to Emeritus Professor Sajiro Makino, M. J. A., for critical improvement of the manuscript with expert advice, and to Professor Charles L. Remington for his continuous encouragement.

\section{References}

Ae, S. A.: Spec. Bull. Lep. Soc. Japan, no. 2, p. 75 (1966); no. 5, p. 89 (1971).

Bytinski-Salz, H.: Biol. Zentralbl., 54, 300 (1934).

Bytinski-Salz, H., and Guenther, A.: Z. indukt. Abst. Vererbl., 53, 153 (1930).

Federley, H.: Hereditas, 24, 221 (1938) ; 29, 205 (1943).

- : Soc. Sci. Fenn. Comment. Biol., 9, 1 (1945).

Kawaguchi, E.: Z. Zellforch., 7, 519 (1928).

Kawazoe, A., and Wakabayashi, M.: Coloured Illustrations of the Butterflies of Japan, Hoikusha, Osaka, 422 pp. (1977).

Lorkovic, Z.: Chromosoma, 2, 155 (1941).

-: Glasnik Hrv. Priridosl. Drustvo, Zagreb 2B, 2/3, 57 (1950).

—: Biol. Glasnik, 21, 95 (1968).

Maeki, K.: Trans. Lep. Soc. Japan, 26, 85 (1976).

Maeki, K., and Ae, S. A.: Kwansei Gakuin Univ. Ronko, 11, 111 (1964).

—-: Spec. Bull. Lep. Soc. Japan, no. 2, p. 121 (1966) ; no. 4, p. 131 (1970).

-: Proc. Japan Acad., 51, 577 (1975) ; 52, 236 (1976) ; 52, 308 (1976) ; 52, 509 (1976) ; 52, 567 (1976) ; 53, 71 (1977) ; 53B, 64 (1977) ; 53B, 133 (1977);

54B, 347 (1978) ; 54B, 459 (1978) ; 55B, 64 (1979) ; 55B, 196 (1979).

Maeki, K., and Remington, C. L.: J. Lepid. Soc., 13, 193 (1960).

Makino, S.: A Review of the Crhomosome Number in Animals, rev. ed., Hokuryukan, Tokyo, 300 pp. (1956).

Remington, C. L.: Proc. 10th Int. Congr. Ent., no. 2, p. 787 (1958).

White, M. J. D.: Animal Cytology and Evolution, 3rd ed., Cambridge Univ. Press, 961 pp. (1973). 